\title{
O PARADIGMA ESTÉTICO DE FÉLIX GUATTARI
}

\author{
Vladimir Moreira Lima Ribeiro ${ }^{1}$
}

Universidade do Estado do Rio de Janeiro (UERJ)

(iD) https://orcid.org/0000-0003-3189-0686

E-mail: anarqvlad@hotmail.com

\section{RESUMO:}

O objetivo deste texto é o de abordar a singularidade daquilo que o pensador Félix Guattari chamou de "paradigma estético". Por vezes também chamado de paradigma ético-estético ou político-estético, este paradigma tem a pretensão de funcionar como uma proposição, mais que uma proposta, para suscitar nas mais diversas áreas, campos e práticas a problemática da criação ética e da recriação política, ambas, indissociáveis. Assim, cabe investigar o que se entende por "estética", o que é a arte e quem é o artista deste paradigma. Quais são as motivações, as paisagens e as condições das questões que levaram Guattari a formular esta ideia de um paradigma capaz, a partir da arte, passando pela ética, instaurar um novo modo de pensar a política e de pensar politicamente.

PALAVRAS-CHAVE: Estética; Política; Ética; Existência.

\section{THE AESTHETIC PARADIGM OF FÉLIX GUATTARI}

\begin{abstract}
:
The objective of this text is to address the singularity of what the thinker Felix Guattari called the "aesthetic paradigm." Sometimes also called an ethical-aesthetic or political-aesthetic paradigm, it pretends to function as a proposition, rather than a proposal, to raise in the most diverse areas, fields and practices the problematic of ethical creation and political re-creation, both inseparable. Thus, it is necessary to investigate what is meant by "aesthetics", what is art and who is the artist of this paradigm. What are the motivations, the landscapes and the conditions of the issues that led Guattari to formulate this idea of a paradigm capable, from art, through ethics, to instituting a new way of thinking politics and to think politically.
\end{abstract}

KEYWORDS: Aesthetics; Politics; Ethic; Existence.

${ }^{1}$ Doutor em Filosofia pela Universidade do Estado do Rio de Janeiro (UERJ), Rio de Janeiro - RJ, Brasil. Professor Assistente do Colégio de Aplicação da Universidade Estadual do Rio de Janeiro (CAp-UERJ), Rio de Janeiro - RJ, Brasil e membro do Núcleo de Filosofias da Criação (NFC).

RIBEIRO, Vladimir Moreira Lima. O paradigma estético de Félix Guattari. Griot : Revista de Filosofia, Amargosa - BA, v.19, n.1, p.1-24, fevereiro, 2019. 


\title{
Introdução
}

\begin{abstract}
No lugar de querer fazer reduções da arte através de esquemas políticos, eu preferiria que fizéssemos recomposições políticas através das riquezas da arte (GUATTARI, 1995, p. 10).
\end{abstract}

Na década de 1990 Guattari publica, com Deleuze, o livro O que é a filosofia?, em 1991. No último ano de sua vida, em 1992, sai o livro Chaosmose. O plano de transversalidade do seu pensamento sofre nesse período outra inflexão. Mais uma transformação da ideia de transversalidade ocorrerá. Na entrevista citada algumas vezes nesse trabalho, desse mesmo ano de 1992, Guattari dizia (2013, p. 306): "Hoje, ela [a transversalidade] mudaria ainda com o conceito de caosmose, porque a transversalidade é caósmica, ela está sempre ligada a um risco de mergulhar fora do sentido, fora das estruturas constituídas". Se busquei mostrar que a linha das transformações da transversalidade segue na direção de um aumento crescente da desterritorialização, sempre um "mais de fuga", um fascínio e, ao mesmo tempo, uma tentativa de pensar os processos hiper-desterritorializados, - nas suas transformações dos anos 60,70 e 80, como marca Guattari - com a caosmose não será diferente.

Porém, ela não será uma transversalidade entre instâncias desterritorializadas ou hiperdesterritorializadas. Já não há prefixo que possa ser adicionado para acentuar o grau de intensidade desta grande fuga. $O$ que parece ocupar o lugar, segundo Guattari, é o que ele chama de "movimento do infinito", "metabolismo do infinito", "velocidades infinitas" ou, ainda, "movimento infinito da desterritorialização". Tais expressões estão materializadas, evidentemente, no livro Chaosmose - detidamente trabalhadas no texto intitulado " $O$ novo paradigma estético". E aparecem também em uma conferência realizada por Guattari, apresentando este seu texto e onde se segue um interessante debate. Guattari diz aí, com todas as letras, creio, a chave para a compreensão da transversalidade diante da noção de caosmose. Ele afirma que

\footnotetext{
Este movimento, então, do infinito, é, ao mesmo tempo, um movimento da existência, na medida em que existo o que eu chamo 'uma submersão no caos do universo', uma apropriação dos universos e uma recarga, uma reposicionalidade, de uma complexidade diferenciada, através de mundos subjetivos, estéticos, etc. Portanto, vejo a coexistência entre o movimento infinito do caos e o movimento infinito da complexidade; a afinidade está sempre em uma interface que chamo a submersão caósmica (GUATTARI, 1994, p. 210).
}

A transversalidade, com a caosmose, é, pura e simplesmente, a existência. Transversalidade existencial. Já era, sob a luz de um eterno retorno reavaliador, assim em todas as suas aparições. "Já era": eis aí um modo de dizer que pode atrapalhar, pois ela só pôde se tornar assim, retrospectivamente, por ser, a cada vez, recomposta, reafirmada. A própria ideia de existência se torna apreensível segundo a ideia da transversalidade caósmica. Uma vez que a caosmose é, precisamente, a transversalidade entre os movimentos infinitos do caos e da complexidade.

RIBEIRO, Vladimir Moreira Lima. O paradigma estético de Félix Guattari. Griot : Revista de Filosofia, 
A própria história da construção dessa palavra tenta captar, de modo processual e não dialético, esta conexão entre dois movimentos infinitos no seio do mesmo e indistinguível movimento infinito da existência. Como se o plano de transversalidade fosse uma dobra do plano de existência, este, uma dobra, em sentido inverso e complementar, que vai ao encontro, do plano de transversalidade. Ambos, disfarçados um no outro, formam uma espécie de núcleo da encruzilhada onde outros planos podem e puderam passar. Um plano de imanência filosófico, um plano de referência científico, um plano de composição estético... Como escrevia Deleuze (2003, p. 357), "Félix sonhava, talvez, com um sistema em que certos segmentos seriam científicos, outros filosóficos, outros vividos, ou artísticos, etc. Félix se eleva a um estranho nível que conteria a possibilidade de funções científicas, conceitos filosóficos, experiências vividas, criação de arte".

Mas o que é este movimento do infinito que se confunde com o movimento da existência e que a caosmose funciona como uma espécie de em si e para si das potencialidades de criação e enriquecimento da própria existência? Um movimento, como diz Guattari (1994, pp. 210-211), "intolerável e necessário"; "movimento caósmico". Ou - como também qualifica Guattari (1993, p. 20) - insuportável. "Há algo de insuportável neste ponto de existencialização - insuportável, no sentido literal, de que não há nada a suportar -, não há suporte elementar da caosmose".

A transformação da transversalidade relativa aos anos 90 não deixa de fora o primeiro livro publicado nessa década, antes de caosmose, o último assinado com Deleuze: $O$ que é a filosofia? Aliás, a história dessa noção está intimamente ligada ao trabalho conjunto com Deleuze. É, inclusive, um tanto curioso que a primeira mutação da transversalidade - a noção de máquina - e a última - caosmose - se faça a partir dos trabalhos de Deleuze, de Diferença e Repetição e Lógica do Sentido, onde Deleuze, retomando o Joyce de Finnegans Wake, torna o "caosmos" um conceito filosófico. Evidentemente, há também uma diferença. Pois esta noção de caosmose que aparece nestes últimos períodos de Guattari não deriva, como aquela de máquina, diretamente dos textos de Deleuze que, aliás, pertencem a um período anterior ao encontro da dupla. Ela deriva da conexão com as dobras das noções que Guattari criou ao longo de toda sua obra - e que criou com Deleuze.

Por outro lado, a problemática do infinito, tanto em $O$ que é a filosofia? quanto em Mil Platôs, apareceram fortemente ligadas ao empreendimento dos autores de conceber a arte: o caos e o cosmo na economia do ritornelo. E, de um modo diferente, as caóides (arte, filosofia e ciência), com seus caosmos. $O$ que é a filosofia? pode ser lido como uma exploração detalhada no que consiste a práxis filosófica diante destes movimentos infinitos e existenciais do caos e da complexidade. Mesmo que este livro precise passar por uma concepção das práticas artísticas e também pense a atividade criadora científica, é a filosofia que fulgura ali como atriz principal.

O que muda com o livro de 1992? Chaosmose, talvez, seja uma tentativa de dobrar ainda em outra direção, pois o problema de fato mudou. Não é mais o empreendimento de definição do que consiste a atividade filosófica, de prolongar e alargar o problema da criação fincado em um determinado, específico, mergulho no caos. Por outro lado, não se trata de transformar a arte em "ator principal" em contraste com a filosofia. A principal razão é que o paradigma estético não vai 
contradizer a transversalidade elaborada entre arte, filosofia e ciência, fazendo com que a arte, estrito senso, passasse para uma posição privilegiada, régia.

Só há, penso, uma razão para que a caosmose surja e materialize com intensidade a transformação da transversalidade nesta estreita década de 90. Diria apenas que a abordagem mudou. Ao invés de privilegiar as práxis que mergulham no caos e, evidentemente, sem perder de vista o trabalho nesta direção, Guattari está preocupado com o que sai do caos, com os processos que a ele pertencem. É por isso, creio, que, ao invés da filosofia, da arte e da ciência, Chaosmose indique uma tentativa de repensar a política, a ética e a estética, como modulações de qualquer práxis criadora. A direção da seta mudou. Não mais das práxis em direção aos movimentos infinitos e existenciais do caos e da complexidade. Mas o que sai destes movimentos em direção a toda e qualquer práxis - como um chamado, um apelo.

A estética, nesse sentido, não pode ser confundida com a arte, como uma atividade específica relativa aos artistas. E esse é um dos motivos que implicará, em diversos momentos, que Guattari também afirma e batize esse seu "novo paradigma" de "paradigma político", "ético-político", "ético-estético", "político-estético" etc. É possível notar o tom de retomada, em diversos trechos, do "esquema" de $O$ que é a filosofia?. Como escrevia Guattari (1992, p. 130),

a potência estética de sentir, embora igual em direito às outras - potências de pensar filosoficamente, de conhecer cientificamente, de agir politicamente -, talvez esteja em vias de ocupar uma posição privilegiada no seio dos Agenciamentos coletivos de enunciação de nossa época.

Política, ética e estética são os nomes, as assinaturas, as qualidades que Guattari quer ressaltar em todo ato de criação, seja ele filosófico, científico, artístico ou, segundo os outros campos invocados em Chaosmose, psicanalítico, religioso, macropolítico, técnico-científico... Em todo caso, tudo que pode ter a chance de contribuir, por pouco que seja, para os processos de subjetivação em vias de singularização. Pois, como também afirma Guattari, o problema determinante em Chaosmose permanece sendo aquele anunciado com todo força em Cartographie schizoanalytiques: a produção de subjetividade.

Cartographies schizoanalytiques está em conexão direta com Chaosmose. É aí que essa noção aparece pela primeira vez já como um ensaio de se afastar de visões reducionistas do caos. Depois, identificado com o Plano de consistência. E ainda a questão dos movimentos do infinito, amplamente trabalhados na conexão entre os Universos e os Territórios existenciais. Tudo retorna em Chaosmose. Mas a retomada deste problema e a reexposição destas noções permitirá que o seu pensamento tenha ainda outros alcances. Como sempre no pensamento de Guattari, é o surgimento de novas noções que deverão estar conectas a estas, retomadas, que promoverá novos efeitos, outras eficiências. E a principal noção que vai aparecer em Chaosmose, para dar consistência ao próprio conceito de caosmose, é a noção de "dobragem caósmica" e, com ela, o paradigma estético. 


\section{Uma visão estética do paradigma}

Seria um equívoco grotesco enxergar no paradigma estético a promoção de um novo sujeito revolucionário no pensamento de Guattari, que chegou a ser explícito em relação a isso, com o objetivo de conjurar uma compreensão da proposição de seu paradigma fatalmente condenada a vir a luz: "não se trata de fazer dos artistas os novos heróis da revolução, as novas alavancas da história! A arte aqui não é somente a existência de artistas patenteados mas também de toda uma criatividade subjetiva que atravessa os povos e as gerações oprimidas, os guetos, as minorias..." (GUATTARI, 1992, p. 115).

Como se os esquizos dos anos 60-70, as minorias dos anos 70-80, que substituiriam o proletariado de antes, fossem agora elas mesmas substituídas pelos artistas nos anos 90! O equívoco reside, evidentemente, no fato de pretender encontrar um campo seguro para a resistência: a arte. $\mathrm{E}$ de nada adiante trocar o sujeito revolucionário se o problema revolucionário necessita, cada vez mais para ser retomado a cada vez, passar para o lado dos focos dos processos de subjetivação, novas maneiras de sentir, pensar e agir cujo o sujeito, identificado e identificante, talvez seja um dos pontos menos potentes deste processo, para não dizer que, muitas vezes, ele é a interrupção do processo.

Assim, não são os artistas da arte, como sujeitos da arte, que interessa Guattari. $O$ ponto focal de seu paradigma reside aí: a elaboração de uma concepção de estética que tece relações paradoxais e em múltiplas direções com as significações dominantes da arte e do ser artista. Pois, primeiramente, a arte, no sentido estrito do termo, não é o lugar privilegiado onde o paradigma estético se manifesta ou deveria se manifestar. Como se todas as práticas não-artísticas, como as científicas, estivessem sendo convidadas a perder suas heterogeneidades para tentar se formalizar como arte. $O$ paradigma estético, ao contrário, convida as mais diversas práticas a se recomporem segundo seus próprios valores, naquilo que as práticas possuem de mais próprio. Em As três ecologias, por exemplo, Guattari cita um caso oriundo das ciências ditas duras, para ressaltar justamente o funcionamento de um paradigma estético num terreno nada "artístico"2.

Entretanto, a arte, evidentemente, pode ser um terreno onde o paradigma estético pode se manifestar. Ela também não fica de fora de ser afetada por essa proposição. Pois, igualmente, ela pode ser modelada por paradigmas científicos ou ideológicos que a posicionam como um modelo, onde todo tipo de reificação e mistificação universalista está pronta para proliferar: os universais do belo, os universais de um conhecimento transcendental revelado e imediato, os universais das leis particulares do mercado de arte, os universais da "cultura" burguesa: arte como domínio de diversão, entretenimento ou erudição do espírito...

Por outro lado, ainda, a palavra estética não cai do céu. Ela vem do domínio da arte, estrito senso mesmo. Mas de um modo tal que talvez seja possível afirmar

\footnotetext{
2 "Paradoxalmente, talvez seja do lado das ciências 'duras' que convém esperar a reviravolta mais espetacular com respeito aos processos de subjetivação. Não é significativo, por exemplo, que em seu último livro Prigogine e Stengers invoquem a necessidade de introduzir na física um 'elemento narrativo', indispensável, segundo eles, para teorizar a evolução em termos de irreversibilidade?", escreve Guattari em As três ecologias (1990, p. 23) pensando em Entre le temps et l'éternité (1988) de Prigogine e Stengers.
}

RIBEIRO, Vladimir Moreira Lima. O paradigma estético de Félix Guattari. Griot : Revista de Filosofia, 
que vem daquilo que na arte já lhe escapa. É nesse sentido, e apenas assim, que a estética do paradigma estético pode ser pensada como uma arte desterritorializada, como a materialização, em ato, de uma linha de fuga da arte. E o que, exatamente, Guattari entende que foge na arte? Guattari não se interessa nem pelo processo criador do sujeito artista, nem, muito menos, pelos consumidores (no sentido amplo do termo). O principal está nos objetos da arte, nas metodologias, nas técnicas, das instâncias criadoras que suportam e se fazem através destes objetos. É a partir destes que uma subjetividade parcial criadora pode se instalar. Toda história que conduz para uma particularização da estética e delimitação da arte está calcada em um enquadramento do objeto artístico, secundário ao processo de criação. Do ponto de vista de Guattari, as instâncias criadas são, justamente, aquilo que sustenta o processo de criação. E é essa sustentação que Guattari tem interesse em revisitar - o que vai chamar de metodologia existencial, micropolítica existencial.

Talvez, a arte, na multiplicidade de suas expressões, seja privilegia por Guattari por manter, de modo ora extremamente consistente, ora rarefeito, a problemática da experimentação contínua, tateante, polifônica e multireferencial do ato de criação no que ele tem não de milagroso, sublime ou espontâneo, mas das texturas heterogêneas, das coordenadas radicalmente novas, dos modos de sentir e valorar a existência que ele não só faz nascer como faz persistir, percutir e repercutir através de um material sensível: seus objetos.

\footnotetext{
É evidente que a arte não detém o monopólio da criação, mas ela leva ao ponto extremo uma capacidade de invenção de coordenadas mutantes, de engendramento de qualidades de ser inéditas, jamais vistas, jamais pensadas. $\mathrm{O}$ limiar decisivo de constituição desse novo paradigma estético reside na aptidão desses processos de criação para auto-afirmar como fonte existencial, como máquina autopoiética (GUATTARI, 1992, p. 135).
}

Existem os objetos da arte, criados pelos artistas. E existe o objeto do paradigma estético, que capta o ato de criação antes que ele seja atribuído ao domínio, ou meio, em que é criado, objetos da arte ou não. Se o paradigma estético é uma generalização desse processo, não é porque ele toma como modelo os objetos e aplica a outros domínios. Mas porque os objetos da arte parecem, talvez mais que os outros, o que constituiria sua única vantagem, tornar explícito o processo imediatamente existencial e ontológico de que são frutos ao seu manifestarem: uma estranha gratuidade absoluta, fruto de uma intensa necessidade, de uma obstinação, para fazer com que algo surja em profundo desacordo como os habituais modos de reger e sentir o mundo. Guattari cita Marcel Duchamp a este respeito: "a arte é um caminho que leva para regiões que o tempo e o espaço não regem" (GUATTARI, 1992, p. 129).

É preciso salientar, ainda, que os objetos artísticos não são outra coisa, diferente do objeto do paradigma estético. Mas é este objeto do paradigma estético que na arte, intensificado por ela, já lhe foge, já não lhe pertence, já lhe escapa. É justamente esta dimensão que mais interessa Guattari a partir da arte, no exato ponto em que ela efetua uma "micropolítica existencial" que, no entanto, não lhe é

RIBEIRO, Vladimir Moreira Lima. O paradigma estético de Félix Guattari. Griot : Revista de Filosofia, 
exclusiva $^{3}$. Se uma obra - como um quadro, um livro, uma música - é um objeto artístico pode ser considerada um objeto artístico da arte, devemos reservar a palavra caosmose para designar este objeto estético do paradigma ético-político de Guattari.

\begin{abstract}
A caosmose não oscila, então, mecanicamente entre zero e o infinito, entre o ser e o nada, a ordem e a desordem: ela ressurge e germina nos estados de coisas, nos corpos, nos focos autopoiéticos que utiliza a título de suporte de desterritorialização. Trata-se aqui de um infinito de entidades virtuais infinitamente rico de possível, infinitamente enriquecível a partir de processos criadores. É uma tensão para apreender a potencialidade criativa na raiz da finitude sensível, "antes" que ela se aplique às obras, aos conceitos filosóficos, às funções científicas, aos objetos mentais e sociais, que funda o novo paradigma estético (GUATTARI, 1992, p. 142).
\end{abstract}

Por sua vez, poderiam ser feitas as seguintes questões: quem são os artistas desse objeto estético? Quem é o artista da caosmose em diferença não oposicional com o artista da arte? Quem é o artista do paradigma estético? Não há como responder, delimitando um meio ou domínio específico. E não porque eles sejam inexistentes. $\mathrm{Ou}$, pior, porque existem fora e independente de qualquer meio, qualquer domínio, qualquer disciplina, qualquer práxis criadora - posição transcendente. Eles são transversais aos meios e domínios criadores. E são a estes, ainda que irreconhecíveis ou ilocalizados, que Guattari se dirige. $O$ artista do paradigma estético é o próprio movimento transversal, que percorrer heteróclitos campos de criação. A tarefa é, justamente, se tornar este artista, participar desse movimento: trata-se de se tornar criador - manejando esta dimensão "antes" da obra, quer implique ou não a efetuação de obras - por meio de processos de subjetivação e de enunciação novos, sempre em vias de se ressingularizarem, se heterogeneificarem.

O fato deste artista do paradigma estético não ser localizável ou determinável de uma vez por todas não significa, portanto, que ele careça de consistência. Ao contrário, trata-se, como um objetivo maior do paradigma estético, de engajar, política e eticamente, as teorias e práticas, nos seus domínios e com seus meios, na criação e na catálise de novos focos existenciais. Um pluralismo generalizado das atividades de criação e resistência em que não há espaço para trans ou inter disciplinariedade pois, nestes casos, o que é posto em conexão são as disciplinas já constituídas, fora de suas forças criadoras ou, no máximo, ainda insuficiente, a partir

${ }^{3}$ Guattari (1992a, s/p), diz algo importante acerca disso: “Os artistas, sobretudo após as grandes rupturas conceituais introduzidas por Marcel Duchamp, por John Cage e outros, trabalham cada vez mais sem garantia, sem bases. Eles não possuem normas transcendentes. Eles trabalham a enunciação mesma da relação estética. E, como isso, são as pessoas que, de uma certa maneira, constituem os núcleos os mais corajosos em sua relação de criatividade. Há outros... Existem as crianças na idade de precaução com o mundo. Há os psicóticos que nós falamos. Há os artistas, há muitas pessoas... Os apaixonados, pessoas que estão com Aids, pessoas em vias de morrer... São pessoas que estão em uma relação caósmica com o mundo... Mas os artistas, de uma certa maneira, forjam os instrumentos, traçam circuitos, para poder afrontar essa dimensão de: 'o que eu faço aí?', 'o que eu faço nesse planeta, a que eu posso me ligar?' - a nada de transcendente! Você pode se ligar aos processos imanentes da criatividade. E, assim, a segunda coisa que eu gostaria de dizer é que nesse momento aí, o paradigma estético cai fora da produção das obras estéticas. É algo que trabalha tanto a ciência quanto a pedagogia, o urbanismo, a medicina, a psiquiatria... Porque é uma metodologia, uma metodologia existencial, essa micropolítica existencial que é elaborada, de uma certa maneira, trabalhada, cavada por essa perspectiva estética".

RIBEIRO, Vladimir Moreira Lima. O paradigma estético de Félix Guattari. Griot : Revista de Filosofia, 
de suas obras criadas. A transversalidade implica, muito mais, uma intradisciplinaridade. Como escreve Guattari, "Não se trata mais, então, de se deixar levar por uma interdisciplinaridade aproximativa, mas entrar em uma intradisciplinaridade capaz de atravessar campos heterogêneos, intradisciplinaridade esta que sustenta as mais fortes cargas de "transversalidade" (GUATTARI, 1985, p. $155)$.

O nome para esta conexão possível, promovida pelo paradigma, que atrai para o objeto caósmico existencial todas as práticas inimagináveis, ao passo que reforça uma necessidade delas se distanciarem em suas especificidades ontológicas a partir de suas próprias rugosidades, é justamente a transversalidade ou, como escreve ainda Guattari, transversalidade caósmica.

Daí porque a construção de seu novo paradigma estético é acompanhada de um diagnóstico, tipificado em três Agenciamentos, que analisa as mútuas transformações, potencialidades e aprisionamentos, do objeto estético. Como a necessidade de enquadrá-lo em domínios específicos é correlata tanto de uma individualização da subjetividade criadora quando destituidora das potencialidades da criação generalizada, isto é, por todos os meios e domínios possíveis.

Guattari procura ressaltar esta dimensão e, para isso, parte do diagnóstico de que o enquadramento particularizado e particularizante, hegemônico, no ocidente, é já uma reação as potências transversais da arte (o que vai se tornar a estética) em outros espaços-tempos.

Na história do Ocidente, só tardiamente a arte destacou-se como atividade específica, da ordem de uma referência axiológica particularizada. Nas sociedades arcaicas, a dança, a música, a elaboração de formas plásticas e de signos no corpo, nos objetos, no chão, estavam intimamente mescladas às atividades rituais e às representações religiosas. Da mesma forma, as relações sociais, as trocas econômicas e matrimoniais não eram muito discerníveis do conjunto da vida daquilo que propus chamar de Agenciamentos territorializados de enunciação. Através de diversos modos de semiotização, de sistemas de representação e de práticas multireferenciadas, tais agenciamentos conseguiam fazer cristalizar segmentos complementares de subjetividade, extrair uma alteridade social pela conjugação da filiação e aliança, induzir uma ontogênese pessoal pelo jogo das faixas etárias e das iniciações, de modo que cada indivíduo se encontrasse envolto por várias identidades transversais coletivas ou, se preferirem, na encruzilhada de inúmeros vetores de subjetivação parcial (...) tal interpenetração tampouco deixava muito lugar para a separação de uma esfera estética, distinta de outras esferas: econômicas, social, religiosa, política... (GUATTARI, 1992, p. 127).

Guattari afirma que nem sucintamente irá traçar as vias que desterritorializam este agenciamento territorializado de enunciação, amplamente exploradas em outros textos, por exemplo, talvez a mais explorada, aquela via da axiomatização capitalística, que implica uma desterritorialização destes agenciamentos bem como uma descodificação dos códigos que aí os fluxos mais variados possuem. "Destaquemos apenas que sua evolução geral irá no sentido de acentuar a individuação da subjetividade, uma perda de sua polivocidade" correlata

RIBEIRO, Vladimir Moreira Lima. O paradigma estético de Félix Guattari. Griot : Revista de Filosofia, 
à setorização, autonomização e transcendência dos "universos de valor da ordem do divino, do bem, do verdadeiro, do poder..." (GUATTARI, 1992, p. 127).

Seria muito simples identificar o paradigma estético como um apelo ao retorno a esta origem - colocada sob o pedestal da pureza - da arte antes da arte. A posição de Guattari é muito mais complexa. Pois a sua concepção desterritorializada da arte, que culmina na estética do paradigma estético, segue a desterritorialização e só pode surgir nestas condições - destes Agenciamentos territorializados de enunciação. Desse modo, o paradigma estético disputa, no seio dos movimentos de desterritorialização e por sua causa, diretamente com a axiomática capitalística e suas reterritorializações, a função da criação.

Estes agenciamentos territorializados da enunciação, de sociedades précapitalistas ou não-modernas, por exemplo, historicamente ou ontologicamente distantes, também se atritam com esta setorização da arte. Mas como eles poderiam ser "estéticos" se eles não se puseram o problema de uma arte particularizada? Guattari é firme em posicionar a sua perspectiva em um mundo onde a estratificação da arte e a setorização de domínios, a fim de desenvolver sistemas de poder específicos e comunicantes, é a lei. "Não conseguimos evitar estetizar uma arte rupestre, cujo alcance, tudo leva a crer, era essencialmente tecnológico e cultural. Assim, toda leitura do passado é necessariamente sobrecodificada por nossas referências no presente" (GUATTARI, 1992, p. 127).

Não se trata, com isso, nem de um abandono - aí sim, pós-moderno - da conexão com agenciamentos heterogêneos, que culmina na promoção de práticas solipsistas que só reforçam o fato de que entre heterogêneos não pode haver conexão possível, haja vista que não há mais nenhuma lei de unificação a posteriori nem nenhuma grande narrativa racional ou humana, estrutural e primeira, a priori. Por outro lado, a obrigação de levar em conta esta sobrecodificação não é a certeza de uma condenação quanto aos paradigmas estéticos que podem ser desenvolvidos. $O$ objetivo de Guattari está justamente aí: escapar da projeção hierarquizante ou de uma horizontalidade entre circuitos fechados, não distantes, porém isolados. "Tomar o partido de tais referências" - dizia Guattari pensando nas referências que são as nossas - "não significa que tenhamos que unificar ângulos de visão basicamente heterogêneos" (GUATTARI, 1992, p. 127).

O novo paradigma estético surge nesse mundo, além e contra ele. E é na medida em que ele começa a nascer que uma outra conexão pode surgir com estes agenciamentos territorializados. Pois ele pode abrir vias, de conexão, para manter ásperas as distâncias que existem entre modos distintos da enunciação estética e aprender, não propriamente com os modos singulares e inapreensíveis do agenciamento territorializado, mas com esta aspereza que emana do que nele permanece desconhecido. Implicações diretas, assim, no olhar e correlativamente na práxis que se pode adotar perante estes outros modos.

E, ainda um outro efeito, talvez, onde resida o objetivo maior de Guattari: a partir desta práxis, fazer valer a recomposição da estética e da criação no interior da recomposição das práxis existenciais que nos pertencem, da política da produção de subjetividade no interior de nossas subjetividades capitalísticas.

Se não é ilegítimo e se é, sem dúvida, inevitável projetar sobre o passado os paradigmas estéticos da modernidade, isto só pode acontecer com a

RIBEIRO, Vladimir Moreira Lima. O paradigma estético de Félix Guattari. Griot : Revista de Filosofia, 
condição de se considerar o caráter relativo e virtual das constelações de universo de valor, às quais dá lugar este tipo de recomposição (GUATTARI, 1992, p. 129).

Essa heterogeneidade, mais a frente em seu texto, Guattari vai transpor para outras experiências, diferentemente heterogêneas, mas, digamos assim, igualmente heterogêneas àquelas das sociedades arcaicas que ocorrem no seio de nossa civilização. $O$ que constitui a tentativa de definição do que há de mais próprio nesse Agenciamento territorializado de enunciação sem, ao mesmo tempo, unificar os ângulos de visão e as práticas heterogêneas que nele correm.

Voltemos aos Agenciamentos territorializados de enunciação. Eles não
constituem, propriamente ditos, uma etapa particular da história. Se é
verdade que podem caracterizar as sociedades sem escrita e sem Estado, é
verdade também que encontramos remanescências e até renascimentos
ativos deste tipo de Agenciamento nas sociedades capitalísticas
desenvolvidas. Além disso, encontramos aspectos desse mesmo tipo de
subjetividade polissêmica, animista, transindividual, no mundo da
primeira infância, da loucura, da paixão amorosa, da criação artística.
Falaremos aqui, de preferência, de um paradigma proto-estético, querendo
com isso assinalar que não estamos nos referindo à arte institucionalizada,
às suas obras manifestadas no campo social, mas a uma dimensão de
criação em estado nascente, perpetuamente acima de si mesma, potência
de emergência subsumindo permanentemente a contingência e as
vicissitudes de passagem a ser dos universos materiais (GUATTARI, 1992,
p. 130).

Ora, o novo paradigma estético de Guattari vai assumir essa característica. Eis aí uma primeira abordagem de como ele funciona: como foi dito, não diz respeito às obras, aos objetos, de um lado, criados por uma subjetividade individualizada, por outro. Ao contrário, nesse Agenciamento, é possível apreender o objeto estético, caosmótico, em vias de elaboração. Ou melhor, "objetividades-subjetividades são levadas a trabalhar por conta própria, a se encarnar em foco animista: imbricam-se umas com as outras, invadem-se, para constituir entidades coletivas - meio-coisa, meio-alma, meio-homem, meio-animal, máquina e fluxo, matéria e signo" (GUATTARI, 1992, p. 131). O que pode ser, então, nesta situação, um objeto e um sujeito criador? Uma interioridade e uma exterioridade? "Na verdade, não há de fato um exterior: a subjetividade coletiva territorializada é hegemônica; ela rebate os universos de valor, uns sobre os outros, através de um movimento geral de fechamento em torno de si mesma; ela rima os tempos e os espaços ao sabor de suas medidas internas, de seus ritornelos rituais" (GUATTARI, 1992, p. 131).

O que vai acontecer com este Agenciamento? Dito de outra forma: que novos valores vão aplainar os universos de valores imanentes deste Agenciamento territorializado? Como vimos, os universos de valores são constituídos, são funtores, da ordem do infinito. E, segundo Guattari, quando entrar em cena um novo agenciamento, os universos de valores se transformaram, serão decalcados por universais. Os valores, de autoreferência, se modificam para valores de transcendência. Não só a particularização ganha poder, como o poder das significações dominantes necessita desta setorização uma vez que em cada setor, em

RIBEIRO, Vladimir Moreira Lima. O paradigma estético de Félix Guattari. Griot : Revista de Filosofia, 
cada faculdade, em cada domínio, vão se instalar entidades transcendentes de referência. Mudou, completamente, o modo de dar sentido e valor na situação que Guattari irá chamar de Agenciamentos maquínicos desterritorializados.

Com os Agenciamentos maquínicos desterritorializados, cada esfera de valorização erige um pólo de referência transcendente autonomizado: o Verdadeiro das idealidades lógicas, o Bem do desejo moral, a Lei do espaço público, o Capital do cambismo econômico, o Belo do domínio estético... Este recorte de transcendência é consecutivo a uma individuação de subjetividade, que se encontra ela própria despedaçada em faculdades modulares tais como a Razão, a Afetividade, a Vontade... A segmentação do movimento infinito de desterritorialização é, portanto, acompanhada por uma espécie de reterritorialização incorporal, por uma reificação imaterial (GUATTARI, 1992, p. 132).

Mesmo tendo sua gênese no seio de um agenciamento dado, "o valor transcendente, por sua vez, coloca-se como inamovível, tendo sempre estado aí e aí devendo permanecer para sempre" (GUATTARI, 1992, p. 133). As transformações vão na dupla direção do objeto considerado e da subjetividade considerada. Do lado do objeto, ele perde toda e qualquer riqueza sensível, toda textura qualificada, para ser subsumido a reificação imaterial dos valores transcendentes. Pois os valores transcendentes possuem a característica marcante de conseguirem se reproduzir independente da contínua criação, do devir, do material sensível.

A valorização que, na figura precedente, era polifônica e rizomática, se bipolariza, se maniqueíza, se hierarquiza, particularizando seus componentes, o que de certo modo tende a esterilizá-la. Dualismos sem saída - como as oposições entre o sensível e o inteligível, o pensamento e a extensão, o real e o imaginário - induzirão o recurso a instâncias transcendentes, onipotentes e homogenéticas, como Deus, o Ser, o Espírito Absoluto, o Significante (GUATTARI, 1992, p. 132).

Eles são, de fato, focos onde se desenvolve uma gênese do homogêneo. Não só o homogêneo em relação a si mesmo, pois nada nele sofre alteração - no máximo, um valor transcendente é trocado por outro - mas também, e mais radicalmente, uma homogênese da matéria sensível, um controle das potencialidades expressivas que os fluxos materiais poderiam ter.

A antiga interdependência dos valores territorializados encontra-se então perdida, assim como as experimentações, os rituais, as bricolages que levavam a invocá-las, a provocá-las, correndo-se o risco de que se revelassem evanescentes, mudas ou perigosas (GUATTARI, 1992, pp. 132$133)$.

Em decorrência, também causam profundos efeitos na dinâmica da produção de subjetividade. Pois, ao mesmo tempo em que eles retiram toda imanência entre a multiplicidade dos valores encarnados e em mutação correlativa com as qualidades mais sensíveis dos seres, eles também retiram da subjetividade, que aí aparecia de modo parcial, sua força enunciadora de composições novas. Ao individualizar esta subjetividade polifônica, ao inventar, como escreve Guattari, esta subjetividade

RIBEIRO, Vladimir Moreira Lima. O paradigma estético de Félix Guattari. Griot : Revista de Filosofia, 
modular - e modular porque ela não é sempre a mesma, se reportando e se comportando diferentemente conforme o valor transcendente que rege o domínio que ela entra - este agenciamento maquínico faz com que a subjetividade fique

\begin{abstract}
perpetuamente em falta, culpada a priori ou, na melhor das hipóteses, em estado de "concordata ilimitada" (segundo a fórmula do Processo de Kafka). A "mentira do ideal", como escrevia Nietzsche, se torna "a maldição suspensa acima da realidade". Assim a subjetividade modular não tem mais o controle sobre a dimensão de emergência dos valores, que encontra neutralizada sob o peso das tabelas de códigos, de regras e leis decretadas pelo enunciador transcendente. Esta subjetividade não mais resulta de uma intricação com contornos móveis das esferas de valorização arrimadas às matérias de expressão; ela é recompostas enquanto individuação reificada, a partir de Universais dispostos segundo uma hierarquia arborescente. Direitos, deveres e normas imprescritíveis expropriam as antigas interdições que sempre deixavam um lugar para a conjuração e para a transgressão (GUATTARI, 1992, p. 133).
\end{abstract}

É precisamente este Agenciamento maquínico que realiza uma desterritorialização dos Agenciamentos territoriais de enunciação. Desterritorialização cuja reterritorialização se dá no corpo mesmo do valor transcendente. Mas estes universais não constituem universos. Não estão a disposição para a encarnação em territórios existenciais. Bem diferente, a "individuação modular faz explodir as sobredeterminações complexas entre os antigos Territórios existenciais, para remodelar faculdades mentais, um eu, modalidades de alteridade personológica, sexual, familiar, como peças compatíveis com a mecânica social dominante" (GUATTARI, 1992, p. 133). Ora, literalmente como peças. A individuação modular não necessariamente implica uma individualização, na forma de um sujeito. A sua desterritorialização dos territórios existenciais não requer, no seu funcionamento mais íntimo, uma reterritorialização em algum território, mesmo endurecido. A individuação modular se caracteriza por uma gestão da produção de subjetividade em que aquilo que, a luz do sujeito moderno, pensávamos estar unificado em uma instância transcendente como a própria ideia de sujeito, é articulado e conjugado com toda a dinâmica de reprodução da ordem vigente. As faculdades, os órgãos, os afetos, são particularizados, regidos por uma valorização transcendente. São muitos valores transcendentes, mas uma para cada setor, único em seu departamento.

Talvez o movimento não seja tão simples. O fato é que a primeira das produções, a produção de subjetividade, é dominada por essa desterritorialização absoluta, de tudo e de todos, através dessa verdadeira técnica da individuação modular. Até a sujeição social parece ser, então, um tipo de modulação da servidão maquínica, como havia dito Guattari. Até a individualização pode ser acionada pela dividuação - permanecendo a seu serviço. Não há uma diferença de natureza e nem uma coexistência entre estas duas individuações. Há uma subsunção da individualização, da sujeição, da fabricação de indivíduos e seus papéis e funções específicos, pela individuação modular, dividual, da servidão maquínica. O que ocorre é que esta individuação modular da subjetividade, desterritorialização absoluta de tudo e de todos, onde nada tem ou pode ter consistência, pode chegar a

RIBEIRO, Vladimir Moreira Lima. O paradigma estético de Félix Guattari. Griot : Revista de Filosofia, 
níveis mortíferos. Um "caos capitalístico", como diz Guattari, onde nenhuma complexidade parece estar presente. Caos de todas as relações sociais capitalísticas. Se há um lugar para a sujeição social, é aí que devemos procurar: como uma operação lançada pela servidão para manter um mínimo de sobrevivência, algo a que se agarrar para não ser sugado pelo caos capitalístico. A individuação se serve da individualização como modo de apresentar algo para a produção de subjetividade que concorre diretamente com os territórios existenciais. A ausência de território existencial é sinônimo de um niilismo tão terrificante que nem Nietzsche, nos seus mais severos diagnósticos, poderia imaginar.

Por outro lado, não pode ser "integrada" enquanto tal a presença de territórios existenciais. Estes são o sinal de uma vontade de viver e o índice de uma resistência que deve ser tão logo sufocada, impedida, se possível, de nascer. O que está em seu lugar e que jamais pode ser visto como equivalente senão estas "territorialidades artificiais", "neo-arcaísmos" e sujeições sociais? As funções sociais, as identidades nacionais, os valores tradicionais da família, o julgo dos puros e dos pecadores... toda uma lista infinita de subjetivações que requerem uma individualização, um eu unificante, cumpre esta função: uma espécie de território existencial às avessas, onde essa desterritorialização absoluta deve provocar a sensação de ser levemente atenuada para logo, pelas costas e pela frente, ela renova todo o seu vigor. Talvez seja esta uma das razões pelas quais os movimentos reacionários e fascistas tenham como, diante de uma crise de subjetividade intensificada pelas políticas ultraneoliberais, se propagar velozmente. Mas não tocamos no essencial ao simplesmente - o que constitui uma verdade - denunciarmos que estes movimentos estão a serviço direto de uma maximização do lucro e de um fortalecimento ainda maior das condições jurídicas, ideológicas e políticas com o objetivo de efetuar novos regimes de exploração e dominação. Pois sabemos como os governos de esquerda, por exemplo, podem ser tão eficazes nisso. A mais fundamental aliança do fascismo com as ordens capitalísticas - aliança que deve ser entendida como uma inextricável continuidade - é que ele exerce uma política de terra arrasada, aniquilando corporal e incorporalmente, os processos de subjetivação em dissidência.

Sem nenhum território existencial no caminho, sem modos de valorizar a existência heterogêneos e irredutíveis à valorização capitalística, a desterritorialização absoluta da máquina capitalística corre com ainda mais facilidade, a servidão maquínica e a individuação modular podem desterritorializar ainda mais. Nisso consiste sua revigoração. A revigoração do valor que cria valor para si mesmo. Do único valor que está em uma posição, não de unificação, mas de redundância, espelho $\mathrm{e}$ fonte de todos os valores transcendente. Do valor transcendente do Capital que, ao mesmo tempo, é o único a reger um campo particular e todos os outros. $\mathrm{O}$ modelo da equivalência generalizada. $\mathrm{O}$ dispositivo anti-transversalista por excelência. $O$ suporte do Agenciamento maquínico desterritorializado.

Essa setorização e bipolarização dos valores pode ser qualificada de capitalística em razão do esgotamento, da desqualificação sistemática das matérias de expressão que ela realiza e que as engajam na órbita da valorização econômica do Capital. Este trata num mesmo plano formal os

RIBEIRO, Vladimir Moreira Lima. O paradigma estético de Félix Guattari. Griot : Revista de Filosofia, 
valores de desejo, valores de uso e valores de troca, e faz passar qualidades diferenciais e intensidades não discursivas sob a égide exclusiva de relações binárias e lineares [...] $\mathrm{O}$ significante capitalístico, como simulacro do imaginário de poder nesse tipo de Agenciamento desterritorializado, tem portanto vocação para sobrecodificar todos os outros universos de valor, inclusive os que habitam o campo do percepto e do afeto estéticos [...] Da mesma forma que os Agenciamentos emergentes territorializados, os Agenciamentos capitalísticos desterritorializados tampouco constituem etapas históricas bem delimitadas. (Pulsões capitalísticas são encontradas no interior dos impérios egípcios, mesopotâmicos, chineses e, depois, durantes toda Antiguidade clássica) (GUATTARI, 1992, pp. 133-134).

É a partir daí que se pode posicionar um terceiro tipo de agenciamento, próprio do paradigma estético. É nesse sentido que o paradigma estético rivaliza com a desterritorialização capitalística com seus valores unidimensionais e homogenéticos. $\mathrm{O}$ surgimento de um terceiro agenciamento, assim, não surge com o fim do capitalismo. Como se uma outra etapa histórica, já não aplicada para os agenciamentos precedentes, a ele estivesse correspondida. $O$ paradigma estético não é um programa, uma meta, uma finalidade. Nem tampouco, uma tentativa de reencontro tomado como originário, puro - ainda que bem intencionado - do Agenciamento territorializado.

O terceiro tipo de Agenciamento processual será ainda mais difícil de captar, pelo fato de estar sendo proposto aqui a título prospectivo, unicamente a partir de traços e sintomas que ele parece manifestar hoje. Ao viés de marginalizar o paradigma estético, esse tipo de agenciamento lhe confere uma posição chave de transversalidade em relação aos outros universos de valor, cujos focos criacionistas e de consistência autopoiética ele só faz intensificar. Entretanto, o fim da autarquia e do esvaziamento dos universos de valor da figura precedente não mais constitui sinônimo de uma volta à agregação territorializada dos Agenciamentos emergentes. Do regime da transcendência reducionista não recaímos na reterritorialização do movimento do infinito segundo os modos finitos (GUATTARI, 1992, pp. 134-135).

A transversalidade é a única localização possível deste agenciamento, que atravessa tanto os outros agenciamentos quanto o que há, hoje, de novas criações de subjetividade. Por ser a caosmose o seu material, a própria criação processual, a transversalidade que faz movimentar o paradigma estético vai na dupla direção de uma recomposição das práxis. Por um lado, "a contaminação direta dos outros campos" quando um se aventura a se sintonizar neste paradigma. Ou ainda, "no mínimo o realce e a reavaliação das dimensões criativas que os atravessam a todos" (GUATTARI, 1992, p. 135).

Eis aí mais uma característica que Guattari apreende na arte que será retomada neste paradigma estético: sua capacidade de enfrentamento dos papéis estabelecidos. "Já desde o Renascimento, mas sobretudo durante a época moderna" (GUATTARI, 1992, p. 135). Mas por que a arte, na problemática da invenção de valores em ruptura, ao menos no ocidente, desempenhou tão fortemente esta função de contaminar diretamente outros campos ou, e às vezes simultaneamente, lançar as

RIBEIRO, Vladimir Moreira Lima. O paradigma estético de Félix Guattari. Griot : Revista de Filosofia, 
luzes para as caosmoses criadoras que atravessam todo e qualquer domínio considerado?

Mais uma vez: potencialidade da música a este respeito, como catalizadora de expressões e modos de ser não musicais, que do freejazz ao punk, passando pelo rap e toda a contracultura hippie criaram outros universos de valores bem no meio do olho do furacão, de um momento em que o Agenciamento maquínico desterritorializado ganhou sua forma mais extrema e atual: as sociedades de integração que se formam no ocidente a partir dos anos 70. O rap e o punk foram, sem dúvida, as duas maiores máquinas de guerra que a juventude ocidentalizada teve como dínamo para enfrentar os territórios devastados pelo racismo, pela ausência de futuro, pelas zonas devastadas de guetos e periferias, pela ultraexploração da precarização do trabalho... E se o segundo se autoexplodiu em um tenaz "fascismo de gangue" paranóico, o primeiro permanece, como escrevia Guattari, uma "máquina estética e máquina molecular de guerra - que se pense atualmente na importância, para milhões de jovens, da cultura Rap - [que] pode se tornar uma alavanca essencial da resingularização subjetiva e gerar outros modos de sentir o mundo, uma nova face das coisas, e mesmo um rumo diferente dos acontecimentos" (GUATTARI, 1992, p. $122)$.

É, em todo caso, uma questão difícil a que o paradigma estético nos conduz: "como podemos ainda falar de universos de valor com esse esfacelamento da individuação do sujeito e essa multiplicação das interfaces maquínicas?" (GUATTARI, 1992, p. 137). Como é possível pensar e criar territórios existenciais com seus modos de autovalorização no contexto em que a dissolução do sujeito efetua uma servidão generalizada, ao passo que a retomada do sujeito estabelece uma sujeição social que a revigora?

\section{A transvalorização do paradigma estético}

A partir de qual grade de valores podemos avaliar os valores, qualificar uns de transcendentes outros de imanentes, localizar aqueles que geram impasses e outros que fazem a passagem para novos movimentos existenciais? Qual é o valor dos valores? O único critério, para Guattari, é a capacidade que os valores criados tem em permitir novas valorizações. A avaliação, o critério, portanto, não está em um valor específico, mas na potência de recriação que um valor, criado, consegue fazer persistir. Eis mais uma definição cabível para a heterogêneses.

Esse critério não pertence, por sua vez, a criação propriamente dita dos valores, nem considerado de um ponto de vista particular nem, muito menos, daquele que se pretende universal. "Sigo afirmando esta utopia onde, eu diria, se dá a escolha dos valores dos valores, isto é, a escolha das heterogêneses dos valores". Diz Guattari. "Se trata, hoje, de uma escolha de valores, de uma escolha de valorização dos valores, não sei como formular de outra maneira..." (GUATTARI, 1994, pp. 210212).

Qual critério se teria para tal atividade? O único critério - mas é esquisito usar a palavra "único" para justamente aquilo que mais se aproxima de uma requalificação infinita dos valores - vem da existência. $O$ índice do movimento recriador de sua passagem. $O$ único critério para a escolha dos valores deve obedecer

RIBEIRO, Vladimir Moreira Lima. O paradigma estético de Félix Guattari. Griot : Revista de Filosofia, 
a exigência de continuidade da existência, segundo a sua necessidade, a sua "fome", pela potência em se recriar.

Como não trabalhar essa recriação a não ser por meios específicos, qualificados, particulares, com suas máquinas e, eventualmente, com suas estruturas próprias? Mas não é justamente na conquista de um trabalho dessa recriação que os meios se encontram em um plano de transversalidade axiológico, criacionista, cujo material, para Guattari, é a caosmose? O paradigma estético é, em suma, uma proposição para colar esta caomose na textura dos movimentos em curso no seio dos mais variados agenciamentos, para torná-los movimentos existenciais. $\mathrm{O}$ caráter reativo da valorização capitalística ressente com uma precisão notável esta operação. Ele nasce e pode se prolongar na medida em que cria um abismo entre o que seriam as passagens que instaurariam os encontros das práxis mais variadas com a caosmose. Guattari diz isso, e ainda mais, em uma passagem extremamente bela:

\begin{abstract}
As estratificações sociais estão dispostas de forma a conjurar, tanto quanto possível, a inquietante estranheza gerada por uma fixação, por demais acentuada, à caosmose. É preciso ir rápido, não devemos nos deter aí onde corremos o risco de ser engolidos: na loucura, na dor, na morte, na droga, na extrema paixão... Todos esses aspectos da existência são certamente objeto de uma consideração funcional pelo socius dominante, mas sempre como correlato de um desconhecimento ativo de sua dimensão caósmica. A abordagem reativa da caosmose secreta um imaginário de eternidade, em particular através da mídia de massa, contra a dimensão essencial de finitude da caosmose: a facticidade do ser aí, sem qualidade, sem passado, sem porvir, em absoluto desamparo e, entretanto, foco virtual de complexidade sem limite. Eternidade de um mundo adulto profundamente infantil, que é preciso opor à hiperlucidez da criança em meditação solitária sobre o cosmos ou ao devir criança da poesia, da música, da experiência mística. É somente então - quando, ao invés de reimpulsionar compleições de alteridade e de relançar processos de semiotização, a caosmose se cristaliza, implode em abismo de angústia, de depressão, de desorientação mental - que, sem dúvida, se coloca a questão de uma recomposição de Territórios existenciais (GUATTARI, 1992, pp. 106-107).
\end{abstract}

Daí porque essa utopia que Guattari segue afirmando não se realiza além da valorização capitalística. O que implica uma outra consideração dos três agenciamentos propostos como "três modalidades de práxis e de subjetivação" (GUATTARI, 1992, p. 138). Perguntava Guattari: estes três agenciamentos “participação de uma situação ético-política de fundo que está em jogo e atravessa as diferentes figuras da história?" (GUATTARI, 1994, p. 210). Sim, ele responde. São três opções ético-políticas que atravessam a história, que não se confundem com ela. E que, nesse plano sub-histórico em que se encontram, permitem, inclusive, na direção contrária de cortes originários muito bem definidos, que se localize, no nível histórico mesmo, como dois tipos de agenciamento pode estar presente em um tipo, sufocado, latente, sem ter a força e a expressão suficiente para caracterizar a situação histórica.

O que é interessante notar, talvez, é que o paradigma estético não seja uma meta a ser realizada no terceiro agenciamento, mas um modo da análise de Guattari estabelecer um meio onde os outros agenciamentos podem aparecer sob o mesmo

RIBEIRO, Vladimir Moreira Lima. O paradigma estético de Félix Guattari. Griot : Revista de Filosofia, 
eixo, em relação com o metabolismo do infinito, com os movimentos existenciais. $O$ terceiro agenciamento pode, assim, ser posicionado, transversalmente, em qualquer agenciamento, com a única condição de que o paradigma estético passe a funcionar seja como análise, seja no seio das próprias práticas que compõe o agenciamento considerado. "Toda a questão do horizonte axiológico desta terceira figura de agenciamento localiza, precisamente, em como pode surgir um novo paradigma estético, político, ético e terapêutico" (GUATTARI, 1994, p. 212).

Por outro lado, a coexistência em um mesmo plano cujo horizonte criacionista diz respeito ao terceiro agenciamento não pretende nem se igualar ao primeiro agenciamento nem se autoposicionar, do ponto de vista histórico, como uma superação do segundo. Ao contrário, é este segundo agenciamento que passa ao primeiro plano, que se destaca. Essa fascinação pelo caos, pela abolição imediata dos processos que, no entanto, concorrem simultaneamente com a possibilidade de uma complexidade e riqueza inaudita marca a tensão entre o caos capitalístico e a caosmose. Pois na caosmose, esta mesma abolição deve ser assumida, como foco de finitude e precariedade, tal como a morte para o grupo-sujeito, pronto para renascer e para perseverar apenas sob a consistência de um vir a ser. Mas sob tutela do segundo agenciamento, esta abolição é tecnologia de poder, estratégia de Estado, valor capitalístico. Ela deve ser combatida, mas não desprezada. Ou melhor, nas condições políticas atuais, ela deve ser um ponto que todo ponto de partida não pode desconsiderá-la.

o novo paradigma estético, que coloca a ênfase na produção de heterogeneidade, na recriação da heterogeneidade, não pode negar a segunda fase, não pode voltar a primeira fase e, portanto, quer encontrar novamente uma potência de emergência. Mas a encontrará no contexto de um mundo da técnica, no contexto da desterritorialização dos valores (GUATTARI, 1994, p. 212).

Diante da acentuação dessa abolição, o problema parece mudar: não se trata de perguntar apenas pela natureza do ato de criação, como algo novo pode surgir. Nas condições de sufocamento e aplainamento, de unidimensionalidade generalizada do capitalismo, trata-se de levar a questão de como se pode criar a criação. Como se pode, enfim, recriar? Creio que se poderia, inclusive, aventurar-se na hipótese de que, nesse plano sub ou não-histórico, existe o embate entre dois paradigmas. $O$ paradigma estético e o paradigma científico. O paradigma da recriação e o paradigma da abolição e da morte. Como foi dito, a ciência não está condenada. Também ela pode passar pelo paradigma estético. Do mesmo modo que a arte pode estar sintonizada por este paradigma científico.

Mas nota-se que Guattari utiliza, não por acaso, o termo "científico" para qualificar este outro paradigma antagonista. Não escolhe dizer "paradigma cientificista", separando a boa ciência dos seus maus usos. A ciência dogmática e a ciência com "consciência", como somos tentados a esmagar a escolha do seu termo. Pois há uma ruptura introduzida pela ciência, na sua gênese moderna, que tanto do ponto de vista histórico e não-histórico, se confunde com o segundo Agenciamento maquínico desterritorializado, capitalístico. Há a universalização dos valores que só se reificam como tais através da aniquilação e da conjuração de outros universos de

RIBEIRO, Vladimir Moreira Lima. O paradigma estético de Félix Guattari. Griot : Revista de Filosofia, 
valores, provocando sempre uma desconsideração da alteridade e heterogeneidade destes mesmos universos. Nesse sentido, nada mais científico do que a religiosidade neopentencostal, como a igreja que não por ironia do destino se chama Universal. Eis aí, também a razão de um dos seus sucessos em territórios existenciais devastados. Pois, talvez, mais do que apresentar algum valor que ofereceria a possibilidade de um mínimo de territorialidade diante do caos capitalístico, ela faz a gestão deste caos com valores caóticos, mortíferos. Um paradoxo que consiste em dar consistência para a morte, em fazer da contínua devastação dos territórios existenciais um valor que se encarna em um mínimo de territorialidade, de materialidade e sobrevivências reais, igualmente caóticas, segundo o ângulo da subjetividade produzida - espasmos caosmóticos.

Mas não nos enganemos quanto a exclusividade deste paradigma científico, em relação a esta religiosidade, a Ciência e as práticas abertamente capitalísticas. Se ele rivaliza com o paradigma estético é porque ele tem a mesma capacidade diagramática: de inundar todo e qualquer agenciamento. Certamente ele não "atravessa", não passa, transversalmente, como no paradigma estético, em respeito as texturas dos modos de existência que ganham consistência em cada agenciamento. Ele homogeniza. Pode até fazer com que um mínimo de particularidade subsista nos agenciamentos. Mas é para melhor expandir seu poder. Por ser indissociável da valorização capitalística, cada setor, cada particularidade, é convidada a redundar na outra.

Em tempos onde o rolo compressor da homogênese capitalística se acentua, parece haver uma conjunção ainda maior entre os valores universais cujo objetivo é jamais problematizar as funções e lugares que se deve ocupar. A cera nos ouvidos para, em hipótese alguma, escutar a caosmose - ainda que esta cera de homogeneização adoeça profundamente os modos de existência.

Eis que retornamos para o problema de partida da transversalidade caósmica. Pois a figura da abolição e da implosão, tanto quanto a caosmose e a recriação da existência, são tomadas pelo mesmo movimento da existência que é, por Guattari, pensado a partir do metabolismo do infinito. E a aposta em uma resposta para o problema da recriação passa por um modo de tratar o infinito, isto é, a própria recomposição da existência, através da propulsão das duas dobragens da caosmose. Guattari formula o problema da seguinte maneira:

\footnotetext{
Como associar o caráter infinito não-discursivo da textura desses incorporais e a finitude discursiva dos fluxos energéticos-espácio-temporais e de seus correlatos proposicionais? Pascal nos indica uma direção em sua resposta à pergunta: consideras impossível que Deus seja infinito e sem partes?: "Sim, quero então mostrar uma coisa infinita e indivisível. É um ponto se movendo por toda parte com uma velocidade infinita; pois ele está em todos os lugares e por inteiro em cada lugar". Com efeito, apenas uma entidade animada a uma velocidade infinita, quer dizer, não respeitando o limite cosmológico einsteiniano da velocidade da luz, pode pretender suprimir ao mesmo tempo um referente limitado e campo de possíveis incorporais, dando assim crença e consistência aos termos
}

RIBEIRO, Vladimir Moreira Lima. O paradigma estético de Félix Guattari. Griot : Revista de Filosofia, 
contraditórios de uma mesma proposição. Mas com essa velocidade pascaliana desdobrando uma "coisa infinita e indivisível" permanecemos ainda apenas em um infinito ontologicamente homogêneo, passivo e indiferenciado. A criatividade intrínseca ao novo paradigma estético exige redobras mais ativas e mais ativantes desse infinito, e isso em duas modalidades que iremos examinar agora e cuja dupla articulação é característica da máquina no sentido amplo considerado aqui (GUATTARI, 1992, p. 140).

Considerando os três funtores (universos, fluxos e phyluns), já se alude, pela ausência, onde, em qual funtor, esta associação vai ocorrer: nos territórios existenciais. Esse problema posto por Guattari poderia também ser formulado acerca da relação entre a caosmose e os territórios existenciais. A caosmose - que está na encruzilhada entre os funtores ${ }^{4}$ - só pode ganhar suas formas mais enriquecedoras na medida em que uma verdadeira "metodologia existencial", como dizia Guattari, desenvolva modos de trabalhá-la enquanto tal, com ritornelos, na fabricação de um território existencial. Uma relação caósmica com o mundo está presente em situações de ruptura em que as significações dominantes vão para os ares ou não conseguem grudar na pele das entidades. Mas um trabalho, uma práxis, dessa mesma caosmose só vai existir, se uma consistência de retomada e recomposição dessa infinita repartida do estado de relançamento se estabelecer através da encarnação de um território existencial. Do contrário, corre-se o risco da caosmose não persistir processualmente, assumindo uma forma espontânea. Ainda que, por outro lado, a caosmose não assumirá, jamais, uma forma organizada, homogênea, reconhecível e identificável. Ela não chega do nada, nem é um ser, dado, pronto para ser conquistado.

Guattari, na conexão com a noção de caosmose, realiza ainda outra vez, uma dobra na noção de máquina: ela aparece como a característica, o nome, a consistência e a qualidade deste trabalho nem espontâneo e nem organizado da caosmose. Maquinismo: "O novo paradigma estético vai produzir a subjetividade maquínica, vai produzir autopoieses em conjuntos que não estão territorializados como na primeira figura de subjetivação" (GUATTARI, 1994, p. 212). Um maquinismo, como "práxis geradora de heterogeneidade e complexidade" não mergulha, mas sai do caos-complexidade como um fazer, uma ação, da existência caosmótica. "A máquina, todas as espécies de máquina estão sempre nessa encruzilhada do finito e do infinito, nesse ponto de negociação entre a complexidade e o caos" (GUATTARI, 1992, p. 139 e p. 141).

É apenas nessa práxis maquínica, dessa encruzilhada, que está algo como o objeto e o sujeito do paradigma estético: a caosmose e a subjetividade maquínica. Mas se pode dizer estas coisas apenas a título de aproximação de um modo novo de pensar. É interessante tentar acompanhar o esforço de Guattari em atravessar a "cortina de ferro ontológica" que fixa de um lado o sujeito, o espírito e de outro o objeto, a matéria. Com a finalidade de posicionar a práxis maquínica da caosmose como um processo que "aglomera essas diferentes enunciações parciais e se instala de algum modo antes e ao lado da relação sujeito-objeto" (GUATTARI, 1992, p. 37). Eis aí, o cerne da transversalidade existencial: caósmica, maquínica.

${ }^{4}$ Tal como a posiciona Guattari (2013) em "L'objet écosophique", último texto de Chaosmose.

RIBEIRO, Vladimir Moreira Lima. O paradigma estético de Félix Guattari. Griot : Revista de Filosofia, 
Semelhante alargamento 'transversalista' da enunciação deveria conduzir ao abandono da 'cortina de ferro ontológica' (segundo a expressão de Pierre Lévy) que a tradição filosófica instalou entre o espírito e a matéria. $O$ estabelecimento de semelhante ponte transversalista move a postular a existência de um certo tipo de entidade que habitaria ao mesmo tempo os dois domínios (GUATTARI, 1994, p. 195-196).

Eis aí o sentido da transversalidade existencial: ela se instaura pela conexão entre a primeira dobragem caósmica e a segunda dobragem caósmica, intitulada autopoiética. A caosmose é justamente esta dobra entre suas duas dobragens, o meio de "dupla imanência" entre as duas. A caosmose, afirmará Guattari, é a "consistência-encruzilhada" (GUATTARI, 1992, p. 161) dos movimentos existenciais.

Este maquinismo, ligado a sua dobragem caósmica, mais do que uma práxis de um sujeito, nos coloca diante de uma práxis da existência sob a forma de uma "subjetividade maquínica" ou, melhor, uma "protosubjetividade maquínica". Autopoiética, uma vez que o movimento existencial estabelece suas próprias consistência criadoras. "A posição autopoiética e 'hipertextual' da máquina possui uma potencialidade pragmática, ela permite ter uma atitude criacionista, de composição maquínica, face a essa cortina de ferro que separa o sujeito, de um lado, as coisas, do outro" (GUATTARI, 2013, p. 119 e p. 229).

A caosmose é imanência entre o caos e a complexidade. Porém, para ela não apagar esta imanência, seja caindo em um caos puro, numa ordem petrificada ou simplesmente fazendo com que o caos e a complexidade tenham uma imanência de vida curta é preciso que a complexidade seja "assumida", como escreve Guattari: "Eu chamaria 'hipercomplexidade' essa complexidade que é mais assumida, que é verdadeiramente dominada e que se encontra em uma relação de insistência, de repetição" (GUATTARI, 2013, p. 120). Mas o que se repete propriamente dito?

Mais do que um objeto, e sob a condição de ser considerado imanente à práxis maquínica, a caosmose revela-se como uma "persistência processual", como uma espécie de "objetividade-subjetividade". Uma vez que sem ganhar a forma de um modo de ser - mesmo que utilize os existentes como suporte de desterritorialização, mesmo que os existentes tenham sua gênese ontológica nela - a caosmose se relança como uma "proto-subjetividade maquínica" dando início ao verdadeiro ponto de partida: recomeço, a recomposição da existência - sua intensificação, seu enriquecimento.

Guattari dizia que as entidades maquínicas são Janus Bifrons. Não poderia ter selecionado melhor a imagem de um deus, senhor das encruzilhadas, das passagens, principalmente, capaz de tornar todo meio um recomeço (GUATTARI, 1992, pp. 106-107). A práxis maquínica, trabalhando a caosmose que dela não pode ser separada, desenvolve uma política da existência ao promover a passagem do "em vias de... do ser" para o "ser em vias de... ser" que, por sua vez, modula as práticas no terreno de uma ética.

É aí que o termo estética aparece em todo o seu esplendor. Deveríamos, talvez, reservá-lo para todo o ciclo recriador que atravessa e arrasta entidades antes e após sua criação, tal como escreve Guattari, inspirado em Janus, da "potência do

RIBEIRO, Vladimir Moreira Lima. O paradigma estético de Félix Guattari. Griot : Revista de Filosofia, 
eterno retorno do estado nascente" (GUATTARI, 1992, p. 119). Mas de uma intensidade tal que nem mesmo o estado nascente é movido por um desejo de eternidade. É preciso que o estado nascente não se transforme em uma fonte segura e originária. Que já sua procura, seu enaltecimento, se confunda com um enfraquecimento do poder do discurso elaborado através desta tomada de posição.

Em outras palavras, é preciso que o eterno retorno não tome o seu eterno como um meio de petrificar e já despontencializar o estado nascente. $O$ renascer do próprio estado nascente só é possível na medida em que a "máquina", como escreve Guattari (1992, p. 49), "é atormentada por um desejo de abolição. Sua emergência é acompanhada pela pane, pela catástrofe, pela morte que ameaça". $\mathrm{O}$ eterno retorno não indica a repetição, mas o valor dos valores, a heterogênese dos valores, a intensidade pela qual a existência carrega e é levada a carregar por meio de uma subjetividade maquínica. Dirá Guattari (1992, p. 73): “existe um 'transversalismo' da intensidade, caracterizado por sua afirmação em diferentes escalas e um 'autopoietismo' que fazem com que a entidade maquínica escape a lógica em que os conjuntos discursivos permanecem sempre enquadrados em coordenadas transcendentes".

Esse é um ponto muito importante. Que lógica é essa que Guattari quer escapar? É a lógica do paradigma científico. A potência deste eterno retorno do estado nascente não é um valor que, posto como inerente a existência, estaria presente inequivocadamente nela, independente dos próprios movimentos existenciais, da própria composição das velocidades infinitas - eternamente presente nela. Como se, não importando os territórios existenciais reais-virtuais, a existência (ou o Ser, o Devir, o Real...) sempre carregasse esta potência do eterno retorno. É assim que o eterno retorno do estado nascente é tomado sob as cores de algo "já-aî". Eternamente, no sentido em que os valores transcendentes são eternos, é que ele retorna. Um retorno estranho, que não necessita das ações de retomada e recomposição, pois, por ser eterno, está, desde sempre, presente. Não há melhor maneira de matá-lo.

Não se escapa do paradigma científico mudando o verdadeiro fundamento da existência e, por isso, mantendo um pensamento alimentado por certezas e garantias. Não basta enunciar a saída de uma existência dada, incapaz de criação, regida por valores transcendentes, para uma existência essencialmente criadora. O que implicará na denúncia das razões pelas quais essa criação, fixada eternamente na existência, não salta continuamente aos nossos olhos. Ela estaria encoberta pelo mundo da técnica, no esquecimento do ser ou até, porque não, alienada pela subjetividade capitalística. Muda-se o movimento para permanecer com as delimitações do paradigma científico que, agora, julga como inexistente o Ser, a essência, a verdade. Mas eles são extremamente reais! Pois existem agenciamentos que fabricam a existência assim. E, nesses agenciamentos, regidos pela máquina abstrata do paradigma estético, a existência não é outra coisa falseada: ela é o que é, funciona como é posta para funcionar.

De nada adiantaria opor um eterno retorno do estado nascente, ou da diferença, a um eterno retorno do mesmo se a existência é, em última instância, sobrecodificada por uma paixão de eternidade que lhe determina características anteriores a toda práxis, a toda pragmática. O eterno retorno do estado nascente só

RIBEIRO, Vladimir Moreira Lima. O paradigma estético de Félix Guattari. Griot : Revista de Filosofia, 
se torna potente quando é maquinado, pela subjetividade maquínica, enquanto tal. "A transversalidade jamais dada como "já-aí", mas sempre algo a conquistar através de uma pragmática da existência" (GUATTARI, 1992b, p. 173). O demônio da caosmose sopra, no ouvido das peças da protosubjetividade maquínica, uma questão processual, práxica: isso que você está em vias de criar vai permitir, a cada vez, quantas vezes mais recriações? $O$ criacionismo axiológico da caosmose vai necessariamente junto com um construtivismo radical do maquinismo.

\begin{abstract}
O maquinismo, como entendemos neste contexto, implica um duplo processo autopoiético-criativo e ético-ontológico (a existência de uma "matéria de escolha") estranho ao mecanismo, de modo que o imenso encaixa de máquinas, em que consiste o mundo de hoje, se acha em posição autofundadora de sua passagem ao ser. $O$ ser não precede a essência maquínica; o processo precede a heterogênese do ser (GUATTARI, 1992b, p. 138).
\end{abstract}

E nenhum espaço sobra, com a destituição dos valores absolutos, na edificação de um relativismo existencial generalizado. A transversalidade existencial estabelece uma verdadeira avaliação da existência em vias de se criar segundo o critério das linhas de fuga. Quantas saídas são possíveis quando um ato toma a decisão de uma saída ou várias saídas conectadas? É daí que surge uma "matéria de opção" que cresce exponencialmente com o aumento correspondente dos "coeficientes de liberdade". Esse é o ponto caósmico, ponto "Z ou Zen da caosmose" (GUATTARI, 1992, p. 107) - ora assume formas silenciosas e doces, ora possuem o peso de uma escolha histórica - em que o engajamento em uma práxis processual permite compor a existência sob uma superfície de aposta em outros valores, com outros territórios existenciais de suporte. A práxis da existência, sempre em vias de se recompor, de compor entidades; mas também de impedir a recomposição, na direção de um endurecimento tenaz que ainda assim garante um mínimo de sobrevivência da existência, em que nada de novo passa e que, por isso, fatalmente faz crescer a abolição, mortífera, da existência.

Esse é o ponto limite que podemos enxergar em toda tentativa de Guattari de promover meios capazes, práxis concretas, de recomposição da existência. Por que a análise institucional, a esquizoanálise, a pragmática, a micropolítica, a ecosofia, o paradigma estético, a esquerda, a revolução, molar e molecular, em vez de nada ou de algo já-aí? Se palavras parecem se opor a um outro modo de maquinar as coisas, como a psicanálise ou uma ecologia exclusivamente ambiental, isso ocorre apenas em uma segunda dimensão. Primeiramente, é com a própria existência, com a própria caosmose que é preciso se debater.

Todo um pensamento da transcendência, toda uma sentimentalidade da eternidade, transformaram o progressivismo em uma imensa fobia, um evitamento sistemático da finitude, da inanidade última da existência, magnificamente ilustrada por Samuel Beckett. Ao invés de adoecer, tratase de encontrar uma razão pragmática. Existe aí um salto estético que expropriaria o salto religioso de Kierkegaard. Por que mudar, por que a revolução ao invés de nada? Porque isso soa melhor! Mas, no fundo, para nada, por um prazer imaterial, uma palpitação imperceptível na a superfície das coisas (GUATTARI, 2013, pp. 298-299)

RIBEIRO, Vladimir Moreira Lima. O paradigma estético de Félix Guattari. Griot : Revista de Filosofia, 
Pois como escreviam Deleuze e Guattari (1992c, pp. 89-90), "não há nunca outro critério senão o teor da existência, a intensificação da vida". Se Pascal e Kierkegaard aparecem nas tematizações de Guattari desse limiar existencial é porque eles sabiam bem que "o que se aposta, aquilo sobre o que se aposta, é a existência imanente daquele que crê que Deus exista". Este "sobre", marcado em itálico por Deleuze e Guattari, é muito especial. É sinônimo de uma passagem, de um movimento indireto: através de uma escolha, com uma práxis, passa a aposta e a fé no teor da existência, na sua intensificação. Não se sabe nunca de antemão que existência passa e faz passar. E mesmo com a efetiva passagem, há uma dimensão de relançamento intensivo e processual que permanece desconhecida. Mesmo assim se insiste, sem descanso, nesse movimento da existência de "devires intensivos e processuais". Por isso é que se trata literalmente de uma aposta e uma fé. Gênese de um novo amor do desconhecido... Enfim, "uma política e uma ética da singularidade, em ruptura com o consenso, as tranquilizações infantilizantes destiladas pela subjetividade dominante" (GUATTARI, 1992b, p. 162).

Ou ainda, talvez se possa pensar, que a aposta de Pascal e a fé de Kierkegaard dão lugar, em Guattari, a um novo tipo de aposta, uma nova fé, transmutadas em outros nomes: política-ético-estética que igualmente crê, que aposta, que engaja, se responsabiliza e recria a existência "em suas possibilidades em movimentos e em intensidades, para fazer nascer ainda novos modos de existência" (DELEUZE; GUATTARI, 1992c, p. 91). 


\section{Referências}

DELEUZE, Gilles. Deux régimes de fous. Paris: Les Éditions de Minuit, 2003.

DELEUZE, Gilles e GUATTARI, Félix. O que é a filosofia? São Paulo: Editora 34, 1992c.

GUATTARI, Félix. As três ecologias. São Paulo: Editora Papirus, 1990.

GUATTARI, Félix. Caosmose: um novo paradigma estético. São Paulo: Editora 34, 1992.

GUATTARI, Félix. Cartographies schizoanalytiques. Paris: Galilée, 1989.

GUATTARI, Félix. Entretien avec Félix Guattari à la télévision grecque, 1992a. Disponível em https://www.youtube.com/watch?v=NAahy YZkrAo. Acesso em: 5 set. 2018.

GUATTARI, Félix. "Guattari na Puc". In: Revista Cadernos de Subjetividade, n. 1, v. $1,1993$.

GUATTARI, Félix. Le cinéma, la grand-mère et la girafe. 1995. Disponível em http://www.revuechimeres.fr/drupal chimeres/files/26chil6.pdf. Acesso em: 7 set. 2018.

GUATTARI, Félix. Nuevos Paradigmas, cultura y subjetividade. Buenos Aires: Paidos, 1994.

GUATTARI, Félix. Qu'est-ce que l'écosophie? Paris: Lignes, 2013.

Autor(a) para correspondência: Vladimir Moreira Lima Ribeiro, Universidade do Estado do Rio de Janeiro, Rua Santa Alexandrina, n² 288, Rio Comprido, 20261-232, Rio de Janeiro - RJ, Brasil. anarqvlad@hotmail.com 